\title{
Enhanced recovery of Salmonella Typhimurium DT104 from exposure to stress at low temperature
}

\section{Correspondence \\ Mark A. Jepson \\ m.a.jepson@bristol.ac.uk}

Received 22 September 2010

Revised 14 December 2010

Accepted 17 December 2010

\author{
Suzanne Humphrey, ${ }^{1}$ Leann F. Clark, ${ }^{1}$ Tom J. Humphrey ${ }^{2}$ \\ and Mark A. Jepson ${ }^{1}$ \\ ${ }^{1}$ School of Biochemistry, University of Bristol, University Walk, Bristol BS8 1TD, UK \\ ${ }^{2}$ National Centre for Zoonosis Research, University of Liverpool, Leahurst Campus, Neston, \\ Wirral CH64 7TE, UK
}

Salmonella enterica serovar Typhimurium (S. Typhimurium) remains an important cause of foodborne infection in the developed world. In order to establish infection within a host, Salmonella must survive and recover from a range of environmental stresses. S. Typhimurium strain SL1344 is among the most extensively studied pathogenic Salmonella strains, while S. Typhimurium phage type DT104 is an important type that has been associated with pandemic spread and a high number of food-borne disease outbreaks over the last two decades. In this study, we have compared the abilities of these two $S$. Typhimurium types to recover from stress exposures commonly encountered in food production, including $685 \mathrm{mM} \mathrm{NaCl}, \mathrm{pH} 3.8$, low temperature $\left(6{ }^{\circ} \mathrm{C}\right)$ and combinations thereof. Following removal from prolonged (8 days) stress, DT104 cultures that had been exposed to low temperature, with or without additional stress, resumed exponential growth more rapidly than SL1344 cultures exposed to the same conditions. SL1344 showed higher levels of filamentation than DT104 in response to $\mathrm{NaCl}$ exposure at low temperature. Further, SL1344 incurred higher levels of membrane damage in response to elevated $\mathrm{NaCl}$ and $\mathrm{pH} 3.8$ at both temperatures compared with DT104. However, both strains recovered normal cell division and membrane integrity within $6 \mathrm{~h}$ when all stresses were removed. Expression of the Salmonella pathogenicity island 1 gene $\mathrm{prgH}$, the first gene in the prg/org operon, was monitored using a chromosomal reporter in which $\mathrm{gfp}^{+}$expression was driven by the prgH promoter. Recovery of prgH expression was comparable for SL1344 and DT104 exposed to stress at $22{ }^{\circ} \mathrm{C}$. However, DT104 cultures exposed to $\mathrm{pH} 3.8$ or combined $\mathrm{NaCl}$ and low-pH stress at low temperature resumed $\mathrm{prgH}$ expression more rapidly than SL1344. Both strains recovered maximal levels of prgH expression after $6 \mathrm{~h}$ recovery from all stresses and, interestingly, maximal levels of prgH expression were significantly higher in SL1344, consistent with prgH expression in late-exponential, non-stressed SL1344 and DT104 cultures. Together, these data show that $S$. Typhimurium is capable of rapid recovery from environmental and food-related stresses, and give insight into the enhanced ability of DT104 compared with SL1344 to adapt to such stresses, which may contribute to the success of this globally disseminated pathogenic phage type.

\section{INTRODUCTION}

Non-typhoidal Salmonella continue to be a major cause of food-borne illness in the developed world. In 2008, Salmonella was identified as the causative agent in $53 \%$ of food-borne disease outbreaks in the EU, with 131468 confirmed cases of human salmonellosis reported (Anon, 2010). Despite traditionally being associated with foods of animal origin, foodstuffs such as fresh fruits, vegetables and fruit juices are increasingly recognized as important

Abbreviations: $a_{w}$, water activity; PFA, paraformaldehyde; SPI, Salmonella pathogenicity island; T3SS, type III secretion system. sources of Salmonella enterica infection (Beuchat, 1996; Sivapalasingam et al., 2004; Vojdani et al., 2008). In England and Wales, Salmonella enterica serovar Enteritidis and Salmonella enterica serovar Typhimurium (S. Typhimurium) are among the most important serotypes responsible for human illness (Anon, 2010; Hughes et al., 2007; Threlfall, 2002), with the multidrug-resistant S. Typhimurium definitive type (DT)104 strain now detected frequently among animals raised for food production (Mor-Mur \& Yuste, 2010).

Preservation techniques attempt to produce an environment deleterious for bacterial growth in foodstuffs. However, 
studies have indicated that Salmonella is capable of growth, albeit in the absence of septation, under conditions previously considered bacteriostatic (Mattick et al., 2000, 2003a; Phillips et al., 1998). Little is known about the virulence and invasive capabilities of Salmonella cells under these conditions. Salmonella invasion depends on expression of a type III secretion system (T3SS) encoded on Salmonella pathogenicity island (SPI)-1 (Kubori et al., 1998). While SPI-1 expression is known to be tightly regulated by environmental conditions (Ellermeier \& Slauch, 2007), its response to food preservation conditions remains poorly defined.

S. Typhimurium DT104 achieved pandemic spread during the 1980s and 1990s, and has been associated with outbreaks from a wide range of foods, including beef, raw-milk cheese, pork sausage, meat paste and chicken (Davies et al., 1996; Dechet et al., 2006; Villar et al., 1999; Wall et al., 1994). The reasons behind the success of this particular phage type, and its subsequent decline, are not fully understood (Threlfall, 2000). A study by Wall et al. (1994) concluded that higher rates of morbidity and mortality may be associated with DT104 infection than with those caused by non-DT104 $S$. Typhimurium. Several studies have indicated that DT104 strains are not more invasive in epithelial cells and do not show more extensive intracellular growth in macrophages in vitro than non-DT104 Salmonella (Adaska et al., 2008; Allen et al., 2001; Carlson et al., 2000), and similarly do not show increased virulence in mice (Allen et al., 2001). Further, a number of studies have suggested that DT104 strains do not display higher tolerance than non-DT104 ones to a range of environmental stress conditions, including low $\mathrm{pH}$ (3.5 and 5.0), $2.6 \mathrm{M} \mathrm{NaCl}$ and exposure to hydrogen peroxide (Allen et al., 2001; Fratamico, 2003). As a result, the reasons why DT104 has achieved more successful spread than other Salmonella phage types remain unclear and warrant further investigation. Despite the apparent lack of enhanced stress tolerance in DT104 strains compared with non-DT104 ones, it is possible that DT104 strains are capable of improved recovery from sublethal stress conditions commonly encountered in the environment and in foodstuffs.

S. Typhimurium strain SL1344 is one of the most extensively studied $S$. enterica strains, and is frequently used as a model organism for investigating Salmonella pathogenicity in host cells and in animal models. Accordingly, much of the data that are considered Salmonella dogma have been extrapolated from this strain, with particular emphasis on cell invasion, murine pathogenesis, and SPI-1 expression and regulation. Owing to the large body of data that is available for this strain, SL1344 was selected as a reference strain to enable comparison of behaviour and physiology with DT104 during recovery from exposure to stressful conditions. Strain 16 was selected as a representative DT104-type strain owing to its having the classical multi-antibiotic-resistant phenotype associated with many DT104 strains and its history as an environmental organism (Jørgensen et al., 2000). The presence of strain 16 in sewage indicates that it is present in the environment, likely originating from an infected human or animal, and its ability to invade liver, spleen, ovary, oviduct and muscle tissue in chickens proves its invasive phenotype (Jørgensen et al., 2000; Leach et al., 1999). These features make DT104 strain 16 an appropriate representative strain for testing the response of DT104 Salmonella to stress conditions relevant to food processing.

We have examined the ability of $S$. Typhimurium strains SL1344 (Hoiseth \& Stocker, 1981) and DT104 strain 16 (Leach et al., 1999) to recover from prolonged exposure to stresses common to food production, namely reduced water activity $\left(a_{\mathrm{w}}\right)$, acidic $\mathrm{pH}$ and refrigeration temperature. Exposure to $685 \mathrm{mM} \mathrm{NaCl}$ was selected to model the reduced $a_{\mathrm{w}}$ conditions found in foodstuffs high in salt, such as bacon. Several outbreaks of food-borne disease have been associated with fruit juices (Vojdani et al., 2008), and pH 3.8 was selected to model the level of acidity encountered in orange juice (Croak \& Corredig, 2006), while exposure to low-temperature stress $\left(6^{\circ} \mathrm{C}\right)$ was used to model recovery of Salmonella from refrigeration. The ability of each strain to tolerate prolonged stress exposure, subsequently resume growth and cell division, recover from stress-induced injury and resume SPI-1 virulence gene expression following removal from stress was examined. We found that both $S$. Typhimurium strains, SL1344 and DT104, are capable of resuming exponential growth and normal cell division, recovering from stress-induced injury and recovering maximal SPI-1 expression within $6 \mathrm{~h}$ of removal from stress. Critically, however, these data indicate that recovery from stress at low temperature was consistently more rapid for DT104 than for SL1344, suggesting that such behaviour may provide this organism with an enhanced ability compared with other strains to infect host organisms following exposure to the adverse conditions encountered both in the external environment and in foodstuffs.

\section{METHODS}

Bacterial strains. All strains described in this study were $S$. Typhimurium. Full details of the strains and plasmids used are given in Table 1. For all experiments, strains were grown overnight at $37^{\circ} \mathrm{C}$ as a static culture in Luria-Bertani (Miller) broth.

Preparation of media used for stress exposure. Salmonella was exposed to a range of stress conditions common in food production, namely reduced $a_{\mathrm{w}}$, low $\mathrm{pH}$ or refrigeration temperature, and combinations thereof. $\mathrm{NaCl}$ at $685 \mathrm{mM}(4 \%$, w/v) was selected to model reduced $a_{\mathrm{w}}$ conditions (0.98 relative vapour pressure; Mattick et al., 2000), while pH 3.8 was selected to model acidic foodstuffs such as orange juice (Croak \& Corredig, 2006). These media were prepared by supplementing standard Miller formulation LB (170 mM $\mathrm{NaCl}, \mathrm{pH} 7.0$ ) with either $\mathrm{NaCl}$ or $1 \mathrm{M} \mathrm{HCl}$ to achieve the desired salt concentration and $\mathrm{pH}$. Media were filter-sterilized using $0.2 \mu \mathrm{m}$ poresize filters (Minisart) and stored at $4{ }^{\circ} \mathrm{C}$.

Exposure of Salmonella to prolonged stress. Overnight cultures were prepared by inoculating $10 \mathrm{ml} \mathrm{LB}$ broth with a single colony and incubating for $16-18 \mathrm{~h}$ at $37^{\circ} \mathrm{C}$. Salmonella was centrifuged at $1360 \mathrm{~g}$ for $4 \mathrm{~min}$, and the pellets were resuspended in $10 \mathrm{ml}$ stress media or $10 \mathrm{ml}$ standard LB as a control. Cultures were incubated statically for 8 days at either room $\left(22^{\circ} \mathrm{C}\right)$ or refrigeration $\left(6{ }^{\circ} \mathrm{C}\right)$ temperature. 
Table 1. Bacterial strains and plasmids used in this study

Abbreviations: Amp, ampicillin; Cm, chloramphenicol; Km, kanamycin; Nal, nalidixic acid; Sm, streptomycin; Sp, spectinomycin; Su, sulphonamide; Tet, tetracycline; WT, wild-type.

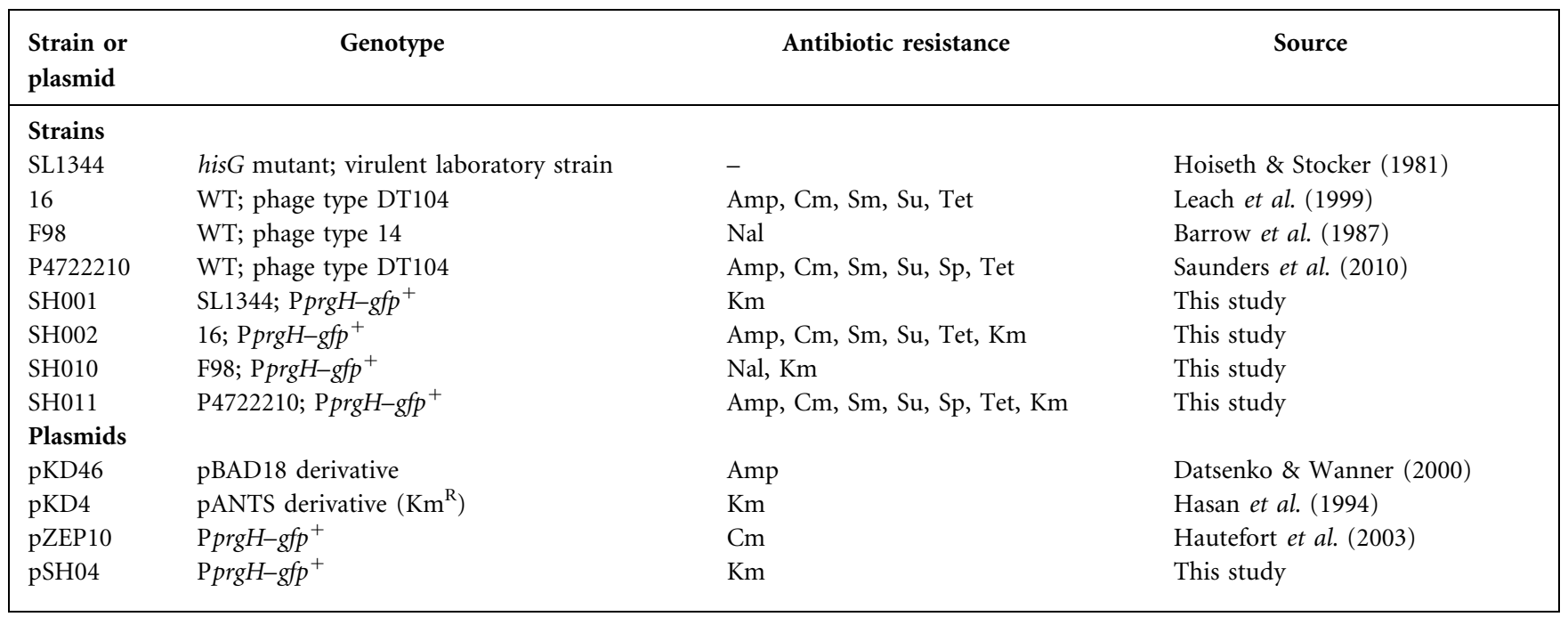

Recovery protocol for Salmonella exposed to prolonged stress. After 8 days, stressed Salmonella was diluted 1:200 (v/v) into $10 \mathrm{ml} \mathrm{LB}$ and allowed to recover at $37^{\circ} \mathrm{C}, 150$ r.p.m. for $6 \mathrm{~h}$. At $2 \mathrm{~h}$ intervals, samples were diluted $1: 3(\mathrm{v} / \mathrm{v})$ in $\mathrm{PBS}_{\text {and }} \mathrm{OD}_{600}$ was measured. At the same time intervals, samples were also assessed for extent of filamentation and their ability to invade epithelial cells.

Assessment of bacterial viability and extent of filamentation. The Molecular Probes LIVE/DEAD BacLight kit for microscopy (Invitrogen) was used to assess the viability of recovering Salmonella cultures. This kit contains a $1: 1(\mathrm{v} / \mathrm{v})$ mixture of SYTO-9 and propidium iodide nucleic acid stains, and was used according to the manufacturer's instructions. The proportions of undamaged and damaged bacteria in each culture were calculated following microscopic enumeration using a haemocytometer and a Leica DM LB2 fluorescence microscope with a $\times 63$ oil-immersion lens. At the same time, the proportion of the population greater than three normal cell lengths was determined to enable calculation of the proportion of filamentous cells present in each sample.

Construction of a single-copy PprgH-gfp ${ }^{+}$reporter. To investigate the promoter activity of the essential SPI-1 gene $\mathrm{prgH}$ during recovery from stress, a single-copy, chromosomally integrated GFP reporter was constructed. All plasmids used in this study are listed in Table 1. Briefly, using oligonucleotides KanR_F1 (5'-CATCAGGATATCCTGCGGCCGCACCAAGCGAACCGGAATTGCCAGC-3') and KanR_R1 (5'-GTCGCCATGATATCACGCTCAGAAGAACTCGTCAAGAAGG-3') (MWG), amplification of the kanamycin-resistance gene from the template plasmid pKD4 (Hasan et al., 1994) was carried out by PCR under standard conditions. The resulting 983 bp product was digested with $E c o R V$ and ligated into an EcoRV-digested pZEP10 vector (Hautefort et al., 2003), generating plasmid pSH04, which was verified by sequencing.

Using oligonucleotides T1_F1 (5'-GCAGGTCACATTTAACGCGGTTGCACAAGTTGCAACATGGCCTGGGGTAATGACTCTCTAGC3') (Hautefort et al., 2003) and KanR_R3 (5'-GACCCGGATAGTAATTTTGCCCGGCCAGATGATAAATCGCGACACGCTCAGAAGAACTCGTCAAGAAGG-3') (MWG), amplification of the fragment containing the $\mathrm{T} 1$ terminator, $p r g H$ promoter $-g f p^{+}$fusion and kanamycin-resistance cassette was performed from pSH04. These primers include 40-42 nt flanking regions at their $5^{\prime}$ ends, producing two regions with exact homology to the putPA locus on the Salmonella LT2 chromosome. The PCR product was integrated into the $S$. Typhimurium SL1344 chromosome using the Lambda Red system (Datsenko \& Wanner, 2000). Transformants were checked by PCR to confirm the presence of the full construct in the correct region of the chromosome. Finally, using P22, the construct was transduced into $S$. Typhimurium SL1344, F98, and DT104 strains 16 and P4722210, producing strains SH001, SH010, SH002 and SH011, respectively.

Quantification of prgH promoter activity in recovering Salmonella populations. At $2 \mathrm{~h}$ intervals during recovery from prolonged stress exposure, $0.5 \mathrm{ml}$ samples of culture were centrifuged at $3293 \mathrm{~g}$ for $2 \mathrm{~min}$, and pellets were resuspended in an equal volume of $2 \%(w / v)$ paraformaldehyde (PFA) in PBS. Following fixation overnight at $4{ }^{\circ} \mathrm{C}$, samples were examined microscopically using a haemocytometer and a Leica DM LB2 fluorescence microscope with $\times 63$ (numerical aperture 1.25) phase-contrast objective. Where necessary, samples were diluted $1: 100$ or $1: 150(\mathrm{v} / \mathrm{v})$ in PBS. The proportion of bacteria with an active prgH promoter, thus GFP-positive, was determined as a percentage of the total number of bacteria.

Salmonella infection of epithelial cells. Madin-Darby canine kidney (MDCK) strain I cells were cultured in Eagle's minimum essential medium (Sigma) supplemented with $2 \mathrm{mM}$ L-glutamine, $10 \%(\mathrm{v} / \mathrm{v})$ fetal calf serum (Biosera), $1 \%$ (v/v) non-essential amino acids (Sigma), $1 \%$ GlutaMAX (GIBCO, Invitrogen Life Science) and $100 \mu \mathrm{g}$ kanamycin $\mathrm{ml}^{-1}$, in $5 \% \mathrm{CO}_{2} / 95 \%$ air. MDCK cells $\left(6.6 \times 10^{4}\right)$ were seeded onto $13 \mathrm{~mm}$ glass coverslips and incubated for 2-3 days. For infection, cells were washed three times and the medium was replaced with $1 \mathrm{ml}$ Krebs' buffer. Stressed and recovering Salmonella cultures were adjusted to $\mathrm{OD}_{600} 0.15 \pm 0.03$ with warm PBS, and $50 \mu \mathrm{l}$ was used to infect the cells at $37^{\circ} \mathrm{C}$ for $15 \mathrm{~min}$ (m.o.i. $\sim 40: 1$ ). Following infection, cells were washed thoroughly in PBS and fixed in $2 \%(w / v)$ PFA overnight. Differential adhered/invaded staining and quantification were carried out as previously described (Clark et al., 2009; Perrett \& Jepson, 2007).

Statistical analyses. Statistical analyses were performed using GraphPad Prism, version 4.0. Two-tailed, unpaired Student's $t$ tests and two-way ANOVA with Bonferroni post-hoc tests were used, with significance set at the $95 \%$ level. 


\section{RESULTS}

\section{S. Typhimurium DT104 exhibits a shorter lag time than SL1344 in resuming exponential-phase growth after prolonged exposure to low-temperature stress}

The ability of S. Typhimurium strains SL1344 and 16 (referred to hereafter as DT104) to tolerate prolonged exposure to stress, and subsequently resume exponential growth following removal from stress, was examined. Salmonella was grown in normal LB, or LB modified to $685 \mathrm{mM} \mathrm{NaCl}, \mathrm{pH} 3.8$, or combined $685 \mathrm{mM} \mathrm{NaCl}$ and $\mathrm{pH} 3.8$, at either 22 or $6{ }^{\circ} \mathrm{C}$ for 8 days, and was subsequently diluted into fresh LB and incubated for $6 \mathrm{~h}$ at $37{ }^{\circ} \mathrm{C}, 150$ r.p.m. $\mathrm{OD}_{600}$ values were measured every $2 \mathrm{~h}$ to monitor growth during stress recovery.

S. Typhimurium strain LT2 has been shown to exhibit a susceptibility similar to that of DT104 isolates when exposed to low- $\mathrm{pH}$ stress $(\mathrm{pH}$ 2.0-3.5) and elevated $\mathrm{NaCl}$ $(2.6 \mathrm{M})$ (Fratamico, 2003). Here, we examined the response of SL1344 and DT104 to more moderate stress conditions. Prolonged exposure to $685 \mathrm{mM} \mathrm{NaCl}$ at room temperature proved to be largely bacteriostatic for both SL1344 and DT104, with significantly $(P<0.01-0.05)$ less growth occurring in both strains during the 8 day period compared with the other stress conditions tested at room temperature (data not shown). No significant differences were observed between SL1344 and DT104 exposed to stress conditions at low temperature, where a decrease in $\mathrm{OD}_{600}$ compared with that of the inoculating culture was observed for all low-temperature conditions (data not shown). These data suggest that low temperature, both itself and in combination with the other stresses, was mildly bactericidal for both strains.

Since SL1344 and DT104 demonstrated similar tolerance to prolonged stress exposure, their ability to resume exponential growth was examined following removal from stress. Growth commenced within $2 \mathrm{~h}$ of removal from the stressful environments for both SL1344 and DT104 that had been exposed to all stress conditions at room temperature (Fig. 1a, b). Growth was comparable at all time points in SL1344 and DT104 cultures recovering from $\mathrm{pH} 3.8$, and combined $\mathrm{NaCl}$ and $\mathrm{pH} 3.8\left(22^{\circ} \mathrm{C}\right)$. In both SL1344 and DT104, the $\mathrm{NaCl}$-stressed $\left(22^{\circ} \mathrm{C}\right)$ culture demonstrated significantly $(P<0.01-0.05)$ slower subsequent growth than the $\mathrm{pH}$ and combined $\left(22^{\circ} \mathrm{C}\right)$ stress cultures, but attained comparable $\mathrm{OD}_{600}$ values after $6 \mathrm{~h}$, which may be a reflection of the bacteriostatic nature of $\mathrm{NaCl}$.

Exposure to stress at low temperature elicited more striking differences in growth recovery patterns between the strains, as DT104 displayed shorter lag times than SL1344 when recovering from all low-temperature stresses. Within $2 \mathrm{~h}$ of removal from stress, DT104 exhibited significantly higher $\mathrm{OD}_{600}$ values for cultures recovering from LB $(P<0.001)$ and $685 \mathrm{mM} \mathrm{NaCl}(P<0.001)$ at low temperature than their SL1344 counterparts (Fig. 1c, d), demonstrating a more rapid return to normal growth. Following $4 \mathrm{~h}$ of recovery, DT104 and SL1344 displayed comparable $\mathrm{OD}_{600}$ values for cultures exposed to $\mathrm{LB}\left(6^{\circ} \mathrm{C}\right)$. However, growth of NaCl-stressed low-temperature DT104 cultures remained significantly $(P<0.01)$ higher than that of SL1344 until 6 h. Similarly, following removal from stress, growth of DT104 cultures exposed to both $\mathrm{pH} 3.8$ and combined $\mathrm{NaCl}$ and $\mathrm{pH} 3.8\left(6{ }^{\circ} \mathrm{C}\right)$ resumed earlier than in SL1344. The differences in $\mathrm{OD}_{600}$ values were not statistically significant until after $4 \mathrm{~h}$ of recovery, when DT104 pH $3.8(P<0.01)$ and combined $\mathrm{NaCl}$ and $\mathrm{pH} 3.8$ $(P<0.001) \quad$ low-temperature cultures had significantly higher $\mathrm{OD}_{600}$ values than their SL1344 counterparts (Fig. $1 \mathrm{c}, \mathrm{d})$. Following $6 \mathrm{~h}$ of recovery, $\mathrm{OD}_{600}$ values were comparable for both strains under all conditions. These data suggest that within 6 h, both SL1344 and DT104 are capable of recovery. However, DT104 demonstrated the ability to recover growth earlier, which may contribute to its ability to cause outbreaks of disease associated with a range of food products. Notably, under normal, nonstressed conditions, no significant differences in growth were observed between the two strains (data not shown).

\section{S. Typhimurium SL1344 displays an increased tendency to form filamentous cells in response to low-temperature stress in comparison with DT104}

Conditions that are suboptimal for Salmonella growth can promote growth in the absence of cell division, producing filamentous cells sometimes up to $200 \mu \mathrm{m}$ in length (Mattick et al., 2000; Phillips et al., 1998). Filamentous cells represent a threat in food microbiology, as biomass can increase in contaminated foodstuffs in the absence of a detectable increase in colony forming units, leading to a potential underestimation of contamination levels. Thus, the predisposition of SL1344 and DT104 to form filaments under food-related stress was examined.

Prolonged culture in modified stressful LB at 22 and $6{ }^{\circ} \mathrm{C}$ produced significantly $(P<0.001-0.05)$ higher levels of filamentation than normal LB $\left(22{ }^{\circ} \mathrm{C}\right)$ culture with both SL1344 and DT104 (Fig. 2). Prolonged culture in normal LB at low temperature induced significantly $(P<0.001)$ higher levels of filamentation than normal LB $\left(22{ }^{\circ} \mathrm{C}\right)$ in SL1344, and marginally higher levels of filamentation in DT104, though not statistically significant. Thus, these data suggest that the conditions tested imposed an additional level of stress over that of normal LB during prolonged culture, and indicate that filamentation is a response to suboptimal growth conditions.

Prolonged culture at room temperature in modified LB containing $685 \mathrm{mM} \mathrm{NaCl}$ or combined $\mathrm{NaCl}$ and low $\mathrm{pH}$ elicited the most dramatic response in both SL1344 and DT104, whereby $21-22 \%$ and $18-25 \%$ of the population produced filaments, respectively (Fig. 2a, b). Recovery of normal cell division (i.e. septation) was similar in both strains, with all cultures containing $<1 \%$ filaments after 
(a) SL1344 $\left(22^{\circ} \mathrm{C}\right)$

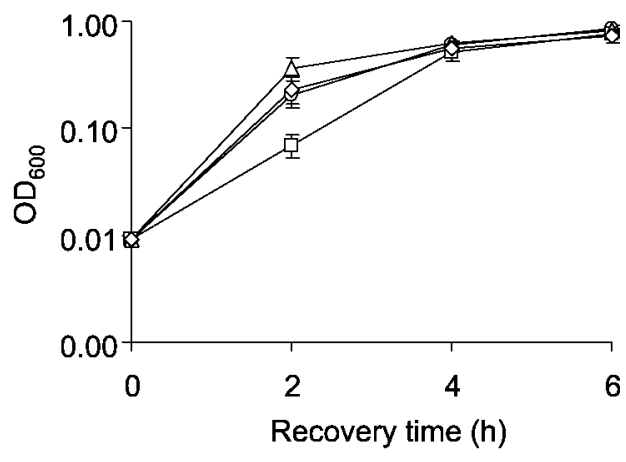

(b) DT104 $\left(22^{\circ} \mathrm{C}\right)$

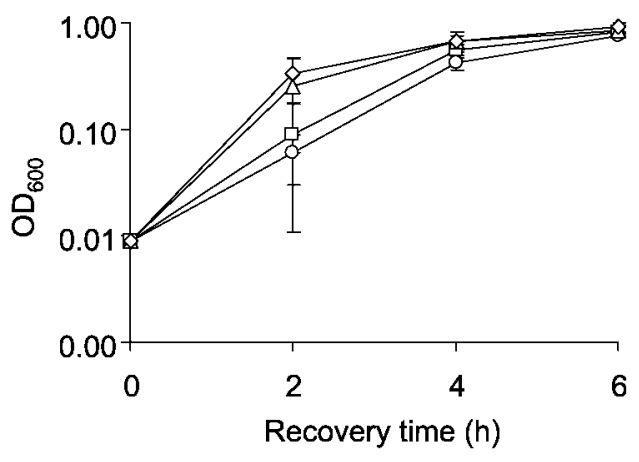

(d) DT104 $\left(6^{\circ} \mathrm{C}\right)$

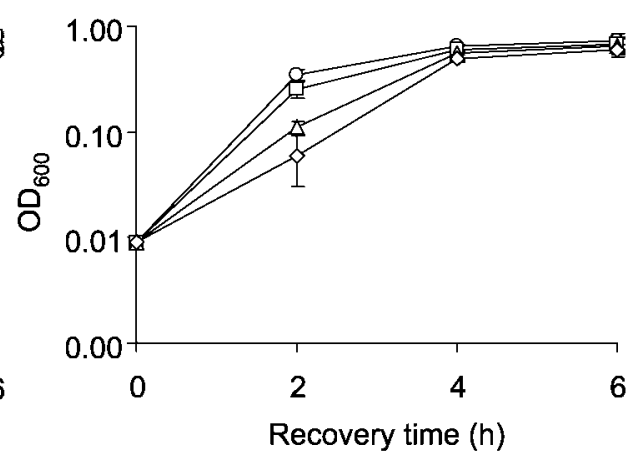

Fig. 1. Recovery of growth following removal from stress in SL1344 and DT104. Salmonella SL1344 (a, c) and DT104 (b, d) were exposed to $\mathrm{LB}(\bigcirc), 685 \mathrm{mM} \mathrm{NaCl}(\square), \mathrm{pH} 3.8(\triangle)$, or combined $685 \mathrm{mM} \mathrm{NaCl}$ and pH $3.8(\diamond)$ at either $22^{\circ} \mathrm{C}(\mathrm{a}, \mathrm{b})$ or $6{ }^{\circ} \mathrm{C}(\mathrm{c}, \mathrm{d})$ for 8 days. Recovery in LB over $6 \mathrm{~h}$ at $37^{\circ} \mathrm{C}$ was monitored at $2 \mathrm{~h}$ intervals by measurement of OD 600 . Data presented are mean $\pm \mathrm{SD}(n=3)$.

$6 \mathrm{~h}$, and with recovery of the $\mathrm{NaCl}$-stressed culture lagging slightly in both strains at $2 \mathrm{~h}$.

As with the resumption of normal growth, the most dramatic differences in filamentation between SL1344 and DT104 were observed in cold-stressed cultures. Exposure to elevated $\mathrm{NaCl}$ produced the highest level of filamentation of all stresses at low temperature in both SL1344 and DT104, which was consistent with the effect of $\mathrm{NaCl}$ exposure at room temperature. However, SL1344 showed significantly higher levels of filamentation than DT104 following exposure to normal $\mathrm{LB}(P<0.001)$ and elevated $\mathrm{NaCl}$ $(P<0.01)$ at low temperature. Despite displaying higher levels of filamentation during exposure to $\mathrm{NaCl}\left(6^{\circ} \mathrm{C}\right)$, SL1344 demonstrated faster recovery of septation, with significantly $(P<0.05)$ lower levels of filamentation after $2 \mathrm{~h}$ of recovery than DT104 recovering from the same stress. SL1344 produced similar levels of filamentation to DT104 in response to $\mathrm{pH} 3.8$, and combined $\mathrm{NaCl}$ and $\mathrm{pH} 3.8$ at low temperature (Fig. 2c, d). Interestingly, the levels of filamentation associated with combined $\mathrm{NaCl}$ and low-pH exposure were significantly lower in SL1344 $(P<0.01)$ and DT104 $(P<0.001)$ cultures incubated at $6{ }^{\circ} \mathrm{C}$ than in those incubated at $22{ }^{\circ} \mathrm{C}$ (Fig. 2). This may be due to the mildly bactericidal effect of this combined stress at low temperature (data not shown), and thus probably reflects the poor growth of both strains during the 8 day culture, resulting in fewer actively growing filamentous cells. SL1344 exposed to combined $\mathrm{NaCl}$ and acid at low temperature recovered more slowly than any other culture, with significantly higher $(P<0.05)$ levels of filamentation than DT104 remaining after $4 \mathrm{~h}$ (Fig. 2c, d). This may reflect the slow growth rate of this culture, as discussed above. Overall, these data suggest that DT104 is more resilient to some stresses at low temperature than the SL1344 reference strain, producing a lower proportion of filaments in response to stress. Over $6 \mathrm{~h}$, all SL1344 and DT104 cultures recovered normal cell division, yielding $<1 \%$ filaments in the population, with most cultures having comparable recovery times.

\section{S. Typhimurium SL1344 exhibits increased susceptibility to stress-induced cell injury compared with DT104}

Filamentation is a response to suboptimal growth conditions, and while this phenotype provides valuable insight into the way in which SL1344 and DT104 grow under stress, measurement of filamentation in the population fails to 
(a) SL1344 $\left(22^{\circ} \mathrm{C}\right)$

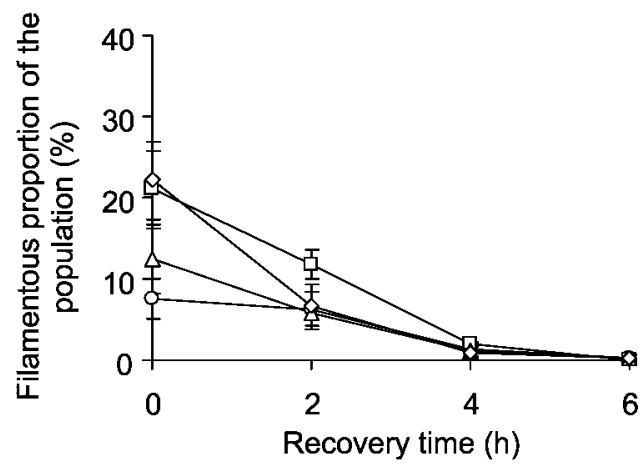

(c) SL1344 $\left(6^{\circ} \mathrm{C}\right)$

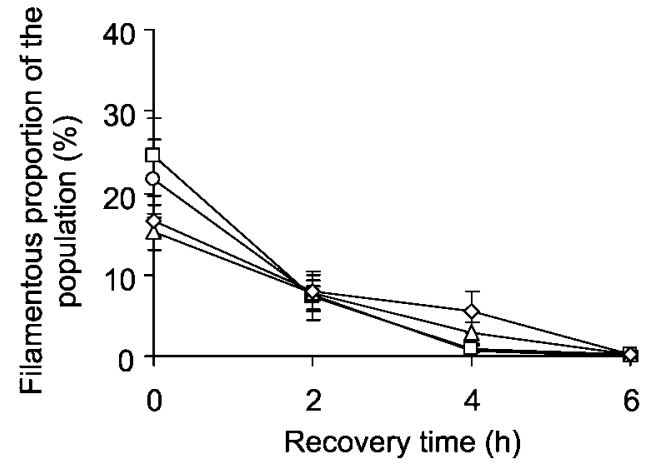

(b) DT104 $\left(22^{\circ} \mathrm{C}\right)$

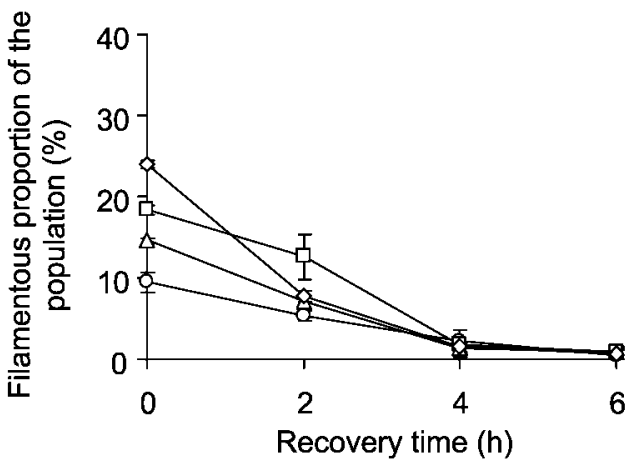

(d) DT104 $\left(6^{\circ} \mathrm{C}\right)$

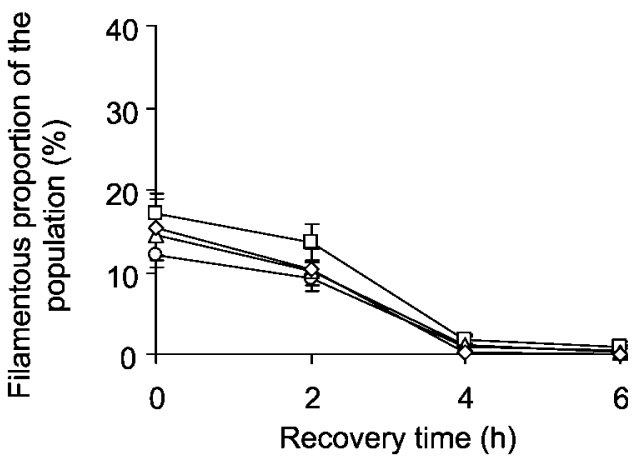

Fig. 2. Recovery of SL1344 and DT104 from stress-induced filamentation. Salmonella SL1344 (a, c) and DT104 (b, d) were exposed to LB $(\bigcirc), 685 \mathrm{mM} \mathrm{NaCl}(\square), \mathrm{pH} 3.8(\triangle)$, or combined $685 \mathrm{mM} \mathrm{NaCl}$ and pH $3.8(\diamond)$ at either $22^{\circ} \mathrm{C}(\mathrm{a}, \mathrm{b})$ or $6{ }^{\circ} \mathrm{C}$ (c, d) for 8 days prior to dilution into LB. Recovery over $6 \mathrm{~h}$ at $37{ }^{\circ} \mathrm{C}$ was monitored at $2 \mathrm{~h}$ intervals by staining with LIVE/DEAD stain and enumerating the proportion of filamentous cells using a haemocytometer. Data presented are mean $\pm \operatorname{SD}(n=3)$.

provide information on the levels of stress-induced cell damage present in each of the cultures. In order to investigate the extent of membrane damage induced in response to, and during recovery from, each of the stress conditions tested, microscopic enumeration of the proportion of cells in each population with damaged membranes was conducted using the LIVE/DEAD stain (Invitrogen).

As expected, prolonged culture in normal LB resulted in the lowest levels of cell injury in both SL1344 and DT104 for any room temperature stress (Fig. 3a, b). The proportion of damaged cells in the population was significantly higher in SL1344 exposed to $\mathrm{pH} 3.8$ $(P<0.001)$ and $685 \mathrm{mM} \mathrm{NaCl}(P<0.05)$ at $22{ }^{\circ} \mathrm{C}$ than in DT104 cultures exposed to the same conditions. The levels of cellular injury induced in response to combined $\mathrm{NaCl}$ and acid at room temperature were higher in DT104 than in SL1344, but this difference was not significant. Irrespective of the stress condition imposed, all SL1344 and DT104 cultures recovered from injury at comparable rates, with no significant differences observed between the strains after $2 \mathrm{~h}$ of recovery.

Prolonged culture of SL1344 and DT104 strains in LB, LB at $\mathrm{pH} 3.8$, or combined $\mathrm{NaCl}$ and $\mathrm{pH} 3.8$ at low temperature produced similar levels of damage, with no significant differences observed between the strains (Fig. 3c, d). Strikingly, exposure of SL1344 to $\mathrm{NaCl}$ at $6{ }^{\circ} \mathrm{C}$ resulted in significantly $(P<0.001)$ higher levels of cell injury than those observed for DT104 exposed to the same stress. As with the room temperature stresses, after $2 \mathrm{~h}$, all SL1344 and DT104 cultures displayed recovery as the damaged proportion of the population began to decrease. Over the $6 \mathrm{~h}$ recovery period a marked reduction in the number of injured cells was evident for both strains, with $<1 \%$ of the population exhibiting damage after $6 \mathrm{~h}$. These data show that Salmonella is capable of rapid recovery from stress-induced injury, and further imply that DT104 is less susceptible than SL1344 to damage from conditions commonly encountered in food production.

\section{Expression of the SPI-1 gene prgH resumes earlier in DT104 cultures recovering from acid stress at $6{ }^{\circ} \mathrm{C}$ than in SL1344 cultures recovering from the same conditions}

DT104 displayed an enhanced ability to resume growth, incurred lower levels of damage and produced fewer filaments compared with SL1344 during exposure to, and 
(a) SL1344 $\left(22^{\circ} \mathrm{C}\right)$

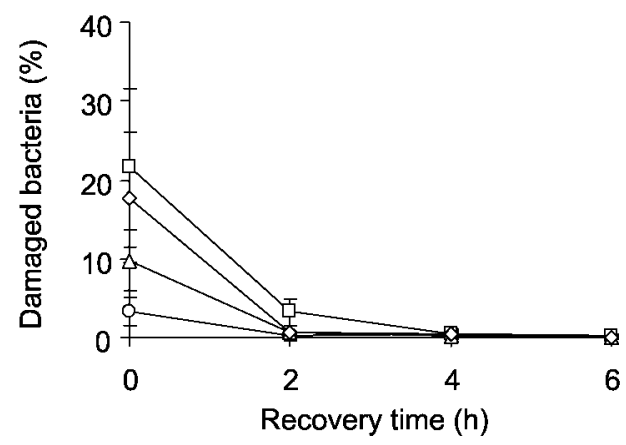

(c) SL1344 $\left(6^{\circ} \mathrm{C}\right)$

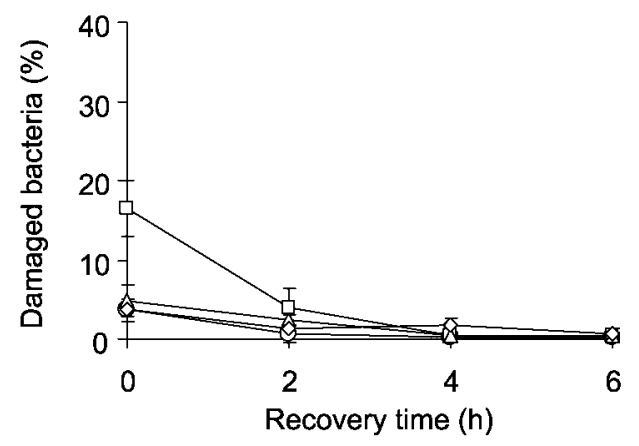

(b) DT104 $\left(22^{\circ} \mathrm{C}\right)$

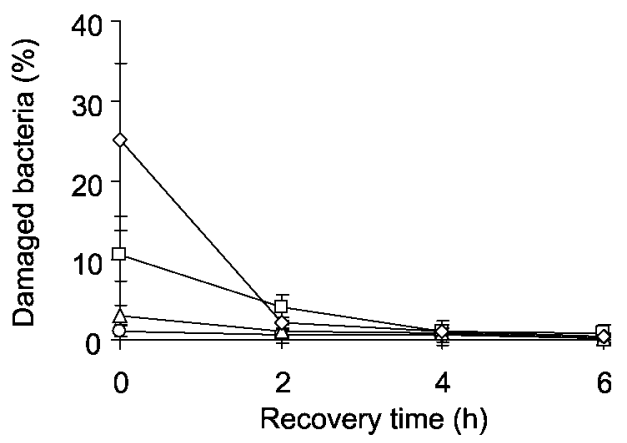

(d) DT104 $\left(6^{\circ} \mathrm{C}\right)$

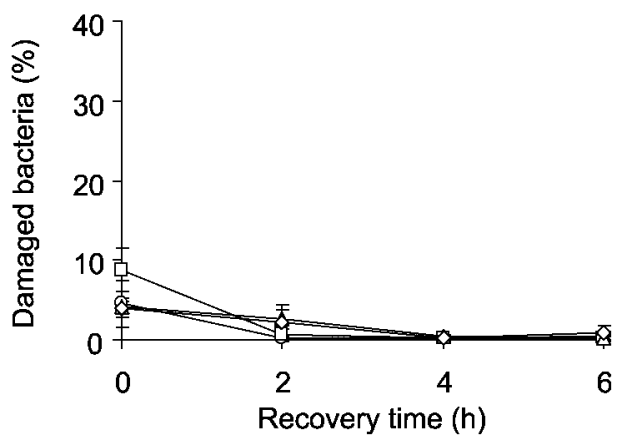

Fig. 3. Recovery of SL1344 and DT104 from stress-induced cell injury. Salmonella SL1344 (a, c) and DT104 (b, d) were exposed to $\mathrm{LB}(\bigcirc), 685 \mathrm{mM} \mathrm{NaCl}(\square), \mathrm{pH} 3.8(\triangle)$, or combined $685 \mathrm{mM} \mathrm{NaCl}$ and $\mathrm{pH} 3.8(\diamond)$ at either $22{ }^{\circ} \mathrm{C}(\mathrm{a}, \mathrm{b})$ or $6{ }^{\circ} \mathrm{C}$ (c, d) for 8 days prior to dilution into LB. Recovery over $6 \mathrm{~h}$ at $37{ }^{\circ} \mathrm{C}$ was monitored at $2 \mathrm{~h}$ intervals by staining with LIVE/DEAD stain and enumeration of the proportion of damaged (red) cells using a haemocytometer. Data presented are mean \pm SD $(n=3)$.

recovery from, a range of stress conditions. The SPI-1 T3SS needle structure required for invasion of non-phagocytic cells is encoded by genes located within the prg/org operon (Klein et al., 2000), and expression of $\mathrm{prgH}$, the first gene in the prg/org operon, is regulated by a graded input system that results in an all-or-nothing output (Temme et al., 2008). This can be exploited to produce a reporter system in which expression of GFP driven by the $\mathrm{prgH}$ promoter enables the proportion of Salmonella positive for P PrgH$g f p$ expression to be used as an index of SPI-1 expression status (Clark et al., 2009; Hautefort et al., 2003; Perrett et al., 2009). Salmonella populations have previously been described as demonstrating heterogeneity of gene expression for $\operatorname{prgH}$, whereby maximal expression (53-70\% positive) occurs in late-exponential phase (Hautefort et al., 2003; Perrett et al., 2009).

Here we created a chromosomal PprgH-gfp ${ }^{+}$construct based on the reporter encoded by the JH3010 strain (Hautefort et al., 2003). Owing to the innate chloramphenicol resistance of our DT104 strain, the JH3010 P prgH-gfp ${ }^{+}$construct was unsuitable for use and the marker was changed to give kanamycin resistance, and the resulting construct was inserted into the chromosome of both SL1344 and DT104, producing strains SH001 and SH002, respectively. Microscopic examination of cultures grown to late-exponential phase indicated that no significant differences in $\mathrm{prgH}$ expression were caused by alteration of the resistance marker, with SL1344 strains $\mathrm{JH} 3010$ and SH001 reporting $62 \%( \pm 0.79 \%)$ and $66 \%$ $( \pm 4.93 \%)$, respectively, of the population positive for prgH expression.

In order to examine the effects of stress exposure on virulence gene expression, $\operatorname{prgH}$ expression levels were examined in each SL1344 (SH001) and DT104 16 (SH002) population during recovery in standard LB at $37{ }^{\circ} \mathrm{C}$. At $2 \mathrm{~h}$ intervals, samples of culture were fixed and the proportion of prgH-positive Salmonella in the population was calculated. Initially, following removal from stress, low levels $(0-3.6 \%)$ of $\operatorname{prgH}$ expression were observed in all SL1344 and DT104 cultures (Fig. 4). Expression of $p r g H$ remained negligible at $2 \mathrm{~h}$ in both SL1344 and DT104 cultures, but after $4 \mathrm{~h}, \operatorname{prgH}$ expression increased in SL1344 (29.5-40.5\%) and DT104 (21.0-33.4\%) recovering from exposure to stress at $22{ }^{\circ} \mathrm{C}$. Importantly, both strains attained expression levels within their typical normal maximal range after $6 \mathrm{~h}$, irrespective of the stress to which they had been exposed.

As above, the most striking differences in recovery between SL1344 and DT104 were observed in cultures recovering 
from stress exposure at low temperature. Similarly to the cultures recovering from stress at room temperature, $\mathrm{prgH}$ expression remained very low after $2 \mathrm{~h}$ (Fig. 4c, d). However, after $4 \mathrm{~h}$ recovery, DT104 cultures displayed significantly higher levels of $\mathrm{prgH}$-positive cells in cultures exposed to $\mathrm{pH} 3.8(P<0.01)$ and combined $\mathrm{NaCl}$ and $\mathrm{pH} 3.8(P<0.001)$ at low temperature. By $6 \mathrm{~h}$, both strains attained expression levels within their typical normal maximal range. Importantly, these data show that upon removal from prolonged stress, both strains are capable of recovering virulence gene expression to levels comparable with their non-stressed, late-exponential phase counterparts.

The ability of strains SL1344 and 16 to invade MDCK epithelial cells was investigated during recovery from combined $685 \mathrm{mM} \mathrm{NaCl}$ and $\mathrm{pH} 3.8$ at $6{ }^{\circ} \mathrm{C}$ in order to address whether differences in prgH expression correspond to differences in SPI-1-mediated invasion. Immediately following removal from stress, no invasion of MDCK cells was observed for either strain. Following $4 \mathrm{~h}$ recovery, DT104 strain 16 was significantly $(P<0.05)$ more invasive in MDCK cells $(0.24 \pm 0.08$ Salmonella per MDCK cell) than SL1344 $(0.04 \pm 0.04$ Salmonella per MDCK cell), demonstrating that the higher levels of $\operatorname{prgH}$ expression observed in strain 16 after $4 \mathrm{~h}$ correspond to an increased ability to invade epithelial cells compared with SL1344 recovering from the same conditions.

Finally, in order to determine whether the differences between SL1344 and DT104 strain 16 in recovery of SPI-1 expression following stress at low temperature are exclusive to these strains or a more general feature of DT104 strains that distinguishes them from non-DT104 strains, $\operatorname{prgH}$ expression was examined in non-DT104 strain F98 (SH010) and DT104 strain P4722210 (SH011). In lateexponential phase cultures, $\operatorname{prgH}$ expression was significantly $(P<0.001)$ higher in the $\mathrm{F98}$ population $(88.1 \pm 7.3 \%)$ than in P4722210 (62.0 $\pm 4.3 \%)$. As observed with strains SL1344 and 16, no significant differences in $\operatorname{prgH}$ expression were observed between F98 and P4722210 during recovery from any stress at $22^{\circ} \mathrm{C}$, or during recovery from $\mathrm{LB}$ or $685 \mathrm{mM} \mathrm{NaCl}$ at $6{ }^{\circ} \mathrm{C}$ (data not shown). $\mathrm{P} 4722210$ recovered prgH expression slightly faster than F98 following exposure to $\mathrm{pH} 3.8$ at $6{ }^{\circ} \mathrm{C}$, recovering maximal levels of $\mathrm{prgH}$ expression by $4 \mathrm{~h}$, while F98 only attained $69.8 \%$ of its maximal expression; however, this difference was not statistically
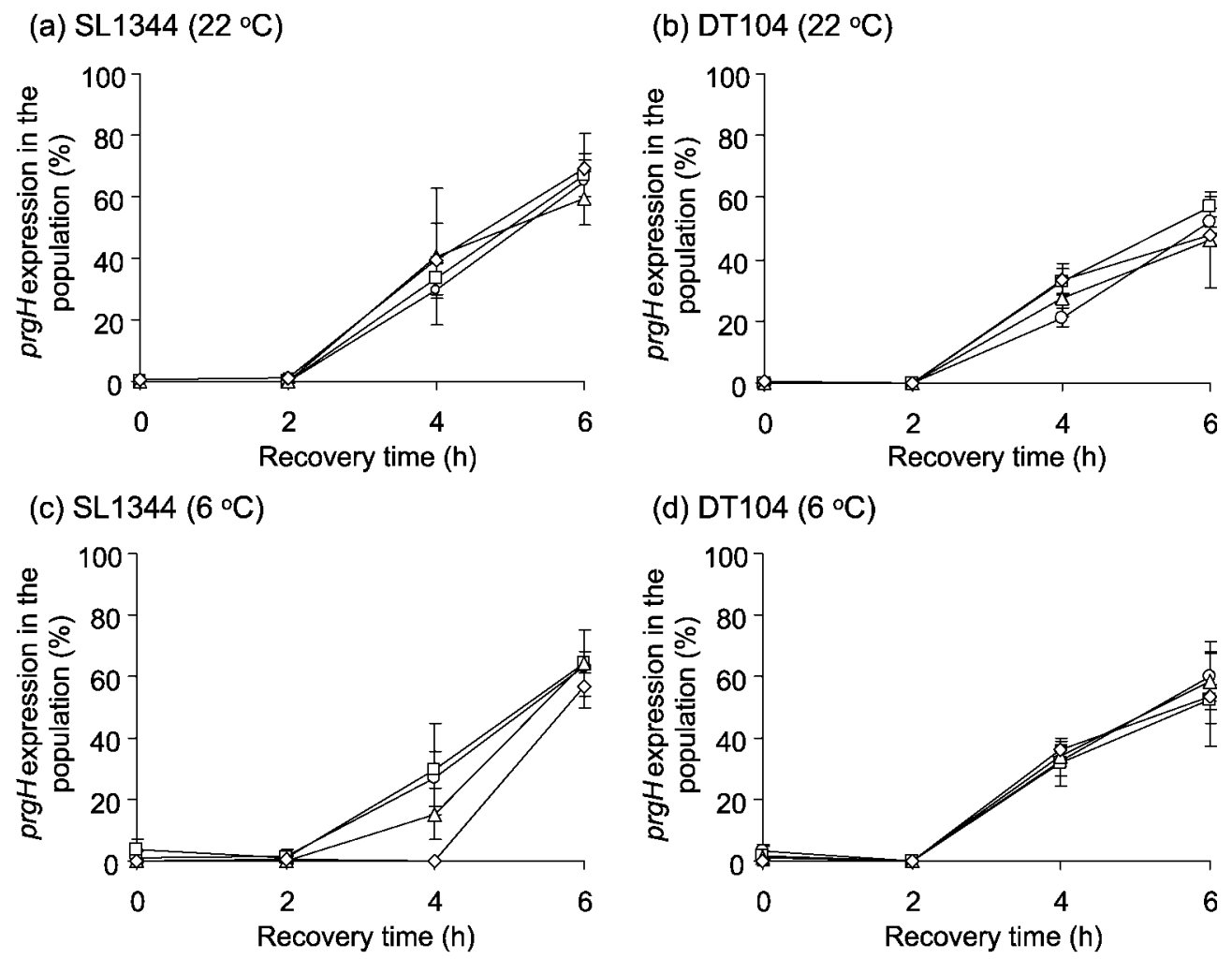

(d) DT104 $\left(6^{\circ} \mathrm{C}\right)$

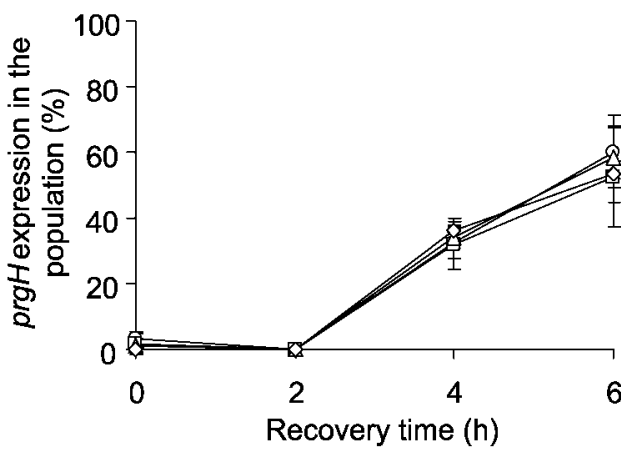

Fig. 4. Recovery of virulence gene expression in S. Typhimurium following removal from stress. Salmonella SL1344 (a, c) and DT104 (b, d) were exposed to LB $(\bigcirc), 685 \mathrm{mM} \mathrm{NaCl}(\square)$, pH $3.8(\triangle)$, or combined $685 \mathrm{mM} \mathrm{NaCl}$ and pH $3.8(\diamond)$ at either $22{ }^{\circ} \mathrm{C}(\mathrm{a}, \mathrm{b})$ or $6{ }^{\circ} \mathrm{C}(\mathrm{c}, \mathrm{d})$ for 8 days prior to dilution into LB. Expression of the virulence gene prgH over $6 \mathrm{~h}$ at $37{ }^{\circ} \mathrm{C}$ was monitored at $2 \mathrm{~h}$ intervals by fixing samples of each culture and enumerating the proportion of prg $\mathrm{H}$-positive cells in the population using a haemocytometer. Data presented are mean $\pm \mathrm{SD}(n=3)$. 
significant. Following recovery from prolonged exposure to combined $685 \mathrm{mM} \mathrm{NaCl}$ and $\mathrm{pH} 3.8$ stress at $6{ }^{\circ} \mathrm{C}$, P4722210 showed significantly higher $(P<0.001)$ levels of $\operatorname{prgH}$ expression at $4 \mathrm{~h}$, attaining $70.4 \%( \pm 8.1 \%)$ of its maximum level, while $\mathrm{F} 98$ recovered only $12.5 \%$ $( \pm 11.3 \%)$ of its maximum prgH expression level. P4722210 recovered maximal prgH expression levels after 6 h; however, F98 only recovered $73-95 \%$ of its maximal prgH expression within $6 \mathrm{~h}$. Together, these data reflect the trend observed with SL1344 and 16 during recovery from combined stress at low temperature, and suggest that the difference in recovery observed between non-DT104 and DT104 Salmonella is not unique to these two strains.

\section{DISCUSSION}

Salmonella is exposed to a multitude of stresses during its life cycle, including those encountered within the host, in the external environment and during food processing (Humphrey, 2004). Accordingly, these micro-organisms have developed an arsenal of stress responses that enable them to tolerate and recover from exposure to suboptimal conditions (Rowley et al., 2006; Rychlik \& Barrow, 2005). During food processing and storage, Salmonella may be exposed to a range of physical and chemical stresses, including extremes of temperature, osmotic shock, hydrostatic pressure, low $\mathrm{pH}$, and the presence of natural antimicrobials and preservatives ( $\mathrm{Wu}, 2008)$. Further, Salmonella must endure exposure to multiple concurrent and/or repeated stress conditions in order to establish infection in the host (Karatzas et al., 2008).

During exposure to stress for 8 days at room temperature, DT104 did not exhibit enhanced growth compared with SL1344. Further, exposure to stress at low temperature for 8 days was mildly bactericidal for both SL1344 and DT104. These results agree with earlier work which suggests that DT104 strains do not exhibit enhanced survival during food-related stress conditions compared with non-DT104 ones (Fratamico, 2003). Crucially, however, our results indicate that DT104 was capable of resuming exponential phase growth more rapidly than SL1344 exposed to stress at low temperature. This may be an important factor for DT104 in foodstuffs and in the environment, as a decreased lag time following a temperature upshift may enable this strain to achieve higher numbers than a non-DT104 strain prior to inoculation into a host, with important implications for infective dose.

Filament formation has been observed in many bacterial species (Hazeleger et al., 2006; Justice et al., 2008; Mattick et al., 2000, 2003b), and is recognized as a phenotype characterized by growth in the absence of cell division under suboptimal conditions (Justice et al., 2008; Mattick et al., 2000; Phillips et al., 1998). Both strains displayed similar levels of filamentation in response to $\mathrm{pH} 3.8$ and combined $\mathrm{NaCl}$ and $\mathrm{pH} 3.8$ stress at low temperature compared with the same stress conditions at room temperature. Levels of filamentation in DT104 cultures exposed to $\mathrm{LB}$ or elevated $\mathrm{NaCl}$ at $6{ }^{\circ} \mathrm{C}$ were similar to those observed at $22{ }^{\circ} \mathrm{C}$. However, the level of $\mathrm{LB}$ and $\mathrm{NaCl}$-induced filaments increased in SL1344 during incubation at low temperature. $\mathrm{OD}_{600}$ values for Salmonella cultures exposed to $\mathrm{pH} 3.8$ and combined $\mathrm{NaCl}$ and $\mathrm{pH} 3.8$ stress at low temperature decreased slightly, but not significantly, more than in $\mathrm{LB}$ or $\mathrm{NaCl}$ cultures exposed to low temperature during the 8 day incubation (data not shown). The increased levels of filamentation observed for SL1344 in LB or NaCl-stressed cultures at low temperature may suggest that more growth occurred in these cultures than in $\mathrm{pH} 3.8$ and combined stress cultures at low temperature. It is possible that this would be reflected in increased levels of filamentation, since cold storage presents an environment suboptimal for normal Salmonella growth. Under certain conditions, namely exposure to low temperature or elevated $\mathrm{NaCl}$ at low temperature, SL1344 exhibited an increased tendency to adopt a filamentous phenotype compared with DT104. Under these conditions, there were no differences in growth between SL1344 and DT104, indicating that the enhanced filamentation in SL1344 was due to defective septation rather than increased growth. We cannot exclude the possibility that this phenotype is a result of the hisG mutation carried by SL1344 but not strain 16, which has been shown to be responsible for filamentation during intracellular growth (Henry et al., 2005). This mechanism seems unlikely, however, given the absence of observable differences in filamentation between SL1344 and strain 16 under the other conditions tested, including those where substantial growth occurred. In DT104 cultures exposed to stress at low temperature, levels of filamentation did not markedly decrease during the first $2 \mathrm{~h}$ of recovery, suggesting that the rapid onset of exponential growth observed for these cultures was not the result of rapid filament septation but resumption of growth prior to septation. This may have major implications for microbial monitoring of foods, since biomass could increase substantially in the absence of a detectable increase in colony forming units within this $2 \mathrm{~h}$ window. These observations add to the growing body of evidence that the presence of filamentous micro-organisms in foodstuffs has important implications for the estimation of the extent of contamination using the colony forming unit assay.

Food preservation techniques rely on the production of an environment deleterious to the growth of micro-organisms. Traditionally, salting, pickling and refrigeration have been considered effective ways to reduce microbial spoilage of foods by producing a bacteriostatic or bactericidal environment. In this study, we have investigated the extent of membrane damage induced in SL1344 and DT104 cultures exposed to such stress conditions, and have demonstrated that SL1344 was more susceptible to stressinduced injury than DT104. Exposure to conditions containing elevated $\mathrm{NaCl}$ appeared to be the most damaging for both strains; however, a striking difference 
was observed between the strains when they were exposed to $\mathrm{NaCl}$ at low temperature, with SL1344 incurring higher levels of damage. This may suggest that DT104 is more tolerant of low-temperature stress conditions than SL1344. However, it is important to note that both strains indicated signs of recovery from all stresses within as little as $2 \mathrm{~h}$ following removal of the stress, with significant decreases in absolute numbers of damaged cells over $6 \mathrm{~h}$. These data imply that Salmonella weakened by stress-induced injury is capable of rapidly repairing membrane damage following removal from stress, and suggest that conditions considered to be bacteriostatic may not be sufficient to prevent salmonellosis.

During infection, Salmonella induces its own uptake into intestinal epithelial cells, a process facilitated by the SPI-1 T3SS needle complex and its effector proteins (Galán, 2001). Regulation of the SPI-1 virulence genes is complex, and conditions that include high osmolarity, decreased oxygen tension, neutral $\mathrm{pH}$ and late-exponential phase growth are known to stimulate their expression (Bajaj et al., 1996; Ernst et al., 1990; Galán \& Curtiss, 1990; Lee \& Falkow, 1990). Previous work using a chromosomally integrated $\mathrm{P} p r g H-g f p$ reporter construct in our laboratory has demonstrated that expression of GFP from the $\mathrm{prgH}$ promoter is closely correlated with the ability to induce membrane ruffles and invade MDCK cells (L. Clark and others, unpublished results). Therefore, this reporter gives a measure of the invasive abilities of recovering SL1344 and DT104 cultures. To our knowledge, this is the first study to use a chromosomally integrated SPI-1 reporter to examine virulence gene expression at the single-cell level in DT104. Expression of $\operatorname{prgH}$ has been shown to be maximal in lateexponential phase in SL1344 (Hautefort et al., 2003). All SL1344 and DT104 cultures recovering from stress appeared to experience an initial lag in resuming $\operatorname{prgH}$ expression, which returned to normal within $6 \mathrm{~h}$. It is likely that this delayed onset of expression is related to recovery of normal growth and cell division, as maximal SPI-1mediated invasion has been shown to be associated with the growth phase (Ernst et al., 1990; Lee \& Falkow, 1990). Critically, our data show that DT104 exposed to pH 3.8 $\left(6{ }^{\circ} \mathrm{C}\right)$ and combined $\mathrm{NaCl}$ and $\mathrm{pH} 3.8\left(6{ }^{\circ} \mathrm{C}\right)$ recovered expression of $\mathrm{prgH} 2 \mathrm{~h}$ earlier than SL1344 exposed to the same stresses. A similar trend was observed for non-DT104 strain F98 and DT104 strain P4722210. These data suggest that DT104 strains are as efficient as non-DT104 strains in resuming SPI-1 expression during recovery from room temperature stress, but are capable of resuming SPI-1 expression more rapidly than non-DT104 strains following prolonged exposure to stress at refrigeration temperature. This may confer a survival advantage upon DT104, enabling faster recovery from stress and thus the ability to resume virulence more rapidly than non-DT104 strains, perhaps contributing to the overall fitness of DT104 strains observed during disease outbreaks.

Here we have shown that both SL1344 and DT104 (16) are capable of recommencing normal growth and cell division, recovering from stress-induced cell damage and resuming normal levels of $\operatorname{prgH}$ expression within a $6 \mathrm{~h}$ period following removal from prolonged stress exposure. Further, we have shown that despite the absence of an obviously enhanced ability of DT104 to grow during exposure to food-related stress, it appears to be capable of more rapid recovery of growth and normal cell division following removal from stress than the reference strain SL1344. Importantly, DT104 appeared to be less susceptible to $\mathrm{NaCl}$-induced damage and produced lower levels of filamentous cells in the presence of $\mathrm{NaCl}$ at low temperature compared with SL1344. For the first time, we have investigated regulation of SPI-1 expression at the single-cell level in DT104 and SL1344 following removal from stress, and have shown that DT104 is capable of resuming virulence gene expression and invasion of epithelial cells more rapidly than SL1344 following exposure to low-temperature stress. These data contribute information to the body of knowledge on DT104, and suggest that part of the reason for the success of this strain on a global level is its ability to recover from stress rapidly, thereby resuming growth and virulence gene expression earlier than non-DT104 strains. This feature of DT104 may result in this strain having a greater ability than other strains to survive and recover from stress in both the environment and the host, thereby leading to more successful dissemination and subsequent disease. Despite their subsequent decline, the explosive emergence of DT104 strains in Europe and the USA has established this group as one of the most important non-typhoidal Salmonella types worldwide (Davis et al., 2002; Glynn et al., 1998; Threlfall, 2002). DT104 boasts resistance to a range of antibiotics, including ampicillin, chloramphenicol, streptomycin, sulphonamides and tetracycline (Davis et al., 2002; Threlfall, 2002), and has been reported to cause more aggressive human disease, associated with higher rates of morbidity and mortality, than other Salmonella strains (Wall et al., 1994). Ultimately, it is important for research to continue into Salmonella strains of particular epidemic success in order that we may gain insight into why certain strains are more successful than others, and therefore enable measures to be taken to contain the spread of Salmonella.

\section{ACKNOWLEDGEMENTS}

We are grateful to the Biotechnology and Biological Sciences Research Council (BBSRC) and Unilever for studentship funding (S.H. and L.F.C.), and to the Medical Research Council (MRC) and Wolfson Foundation for supporting the Wolfson Bioimaging Facility at the University of Bristol. We thank Jay Hinton and Isabelle Hautefort (Institute of Food Research, Norwich, UK) for generously providing the pZEP10 plasmid and GFP-expressing SL1344 (JH3010), and Roberto La Ragione (Veterinary Laboratories Agency, UK) and Tristan Cogan (University of Bristol, UK) for providing DT104 isolates P4722210 and 16, respectively. We also thank Sinead O'Hara, Rebecca Prest, Layla Malt and Katy Jepson for technical assistance, and Isabel Martinez-Argudo and Peter McClure for helpful advice. 


\section{REFERENCES}

Adaska, J. M., Silva, A. J. \& Sischo, W. M. (2008). Comparison of Salmonella enterica subspecies enterica serovar Typhimurium isolates from dairy cattle and humans using in vitro assays of virulence. Vet Microbiol 128, 90-95.

Allen, C. A., Fedorka-Cray, P. J., Vazquez-Torres, A., Suyemoto, M., Altier, C., Ryder, L. R., Fang, F. C. \& Libby, S. J. (2001). In vitro and in vivo assessment of Salmonella enterica serovar Typhimurium DT104 virulence. Infect Immun 69, 4673-4677.

Anon (2010). The Community Summary Report on trends and sources of zoonoses, zoonotic agents and food-borne outbreaks in the European Union in 2008. EFSA Journal 8, 1496.

Bajaj, V., Lucas, R. L., Hwang, C. \& Lee, C. A. (1996). Co-ordinate regulation of Salmonella typhimurium invasion genes by environmental and regulatory factors is mediated by control of hilA expression. Mol Microbiol 22, 703-714.

Barrow, P. A., Tucker, J. F. \& Simpson, J. M. (1987). Inhibition of colonization of the chicken alimentary tract with Salmonella typhimurium Gram-negative facultatively anaerobic bacteria. Epidemiol Infect 98, 311-322.

Beuchat, L. R. (1996). Pathogenic microorganisms associated with fresh produce. J Food Prot 59, 204-216.

Carlson, S. A., Browning, M., Ferris, K. E. \& Jones, B. D. (2000), Identification of diminished tissue culture invasiveness among multiple antibiotic resistant Salmonella typhimurium DT104. Microb Pathog 28, 37-44.

Clark, L., Martinez-Argudo, I., Humphrey, T. J. \& Jepson, M. A. (2009). GFP plasmid-induced defects in Salmonella invasion depend on plasmid architecture, not protein expression. Microbiology 155, 461-467.

Croak, S. \& Corredig, M. (2006). The role of pectin in orange juice stabilization: effect of pectin methylesterase and pectinase activity on the size of cloud particles. Food Hydrocoll 20, 961-965.

Datsenko, K. A. \& Wanner, B. L. (2000). One-step inactivation of chromosomal genes in Escherichia coli K-12 using PCR products. Proc Natl Acad Sci U S A 97, 6640-6645.

Davies, A., O'Neill, P., Towers, L. \& Cooke, M. (1996). An outbreak of Salmonella typhimurium DT104 food poisoning associated with eating beef. Commun Dis Rep CDR Rev 6, R159-R162.

Davis, M. A., Hancock, D. D. \& Besser, T. E. (2002). Multiresistant clones of Salmonella enterica: the importance of dissemination. J Lab Clin Med 140, 135-141.

Dechet, A. M., Scallan, E., Gensheimer, K., Hoekstra, R. Gunderman-King, J., Lockett, J., Wrigley, D., Chege, W., Sobel, J. \& Multistate Working Group (2006). Outbreak of multidrug-resistant Salmonella enterica serotype Typhimurium definitive type 104 infection linked to commercial ground beef, northeastern United States, 2003-2004. Clin Infect Dis 42, 747-752.

Ellermeier, J. R. \& Slauch, J. M. (2007). Adaptation to the host environment: regulation of the SPI1 type III secretion system in Salmonella enterica serovar Typhimurium. Curr Opin Microbiol 10, 24-29.

Ernst, R. K., Dombroski, D. M. \& Merrick, J. M. (1990). Anaerobiosis, type 1 fimbriae, and growth phase are factors that affect invasion of HEp-2 cells by Salmonella typhimurium. Infect Immun 58, 2014-2016.

Fratamico, P. M. (2003). Tolerance to stress and ability of acid-adapted and non-acid-adapted Salmonella enterica serovar Typhimurium DT104 to invade and survive in mammalian cells in vitro. J Food Prot 66, 1115-1125.

Galán, J. E. (2001). Salmonella interactions with host cells: type III secretion at work. Annu Rev Cell Dev Biol 17, 53-86.
Galán, J. E. \& Curtiss, R., III (1990). Expression of Salmonella typhimurium genes required for invasion is regulated by changes in DNA supercoiling. Infect Immun 58, 1879-1885.

Glynn, M. K., Bopp, C., Dewitt, W., Dabney, P., Mokhtar, M. \& Angulo, F. J. (1998). Emergence of multidrug-resistant Salmonella enterica serotype Typhimurium DT104 infections in the United States. N Engl J Med 338, 1333-1339.

Hasan, N., Koob, M. \& Szybalsk, W. (1994). Escherichia coli genome targeting, I. Cre-lox-mediated in vitro generation of ori ${ }^{-}$plasmids and their in vivo chromosomal integration and retrieval. Gene 150, 51-56.

Hautefort, I., Proença, M. J. \& Hinton, J. C. D. (2003). Single-copy green fluorescent protein gene fusions allow accurate measurement of Salmonella gene expression in vitro and during infection of mammalian cells. Appl Environ Microbiol 69, 7480-7491.

Hazeleger, W. C., Dalvoorde, M. \& Beumer, R. R. (2006). Fluorescence microscopy of $\mathrm{NaCl}$-stressed, elongated Salmonella and Listeria cells reveals the presence of septa in filaments. Int $J$ Food Microbiol 112, 288-290.

Henry, T., Garcia-Del Portillo, F. \& Gorvel, J. P. (2005). Identification of Salmonella functions critical for bacterial cell division within eukaryotic cells. Mol Microbiol 56, 252-267.

Hoiseth, S. K. \& Stocker, B. A. D. (1981). Aromatic-dependent Salmonella typhimurium are non-virulent and effective as live vaccines. Nature 291, 238-239.

Hughes, C., Gillespie, I. A., O’Brien, S. J. \& Breakdowns Food Safety, G. (2007). Foodborne transmission of infectious intestinal disease in England and Wales, 1992-2003. Food Contr 18, 766-772.

Humphrey, T. (2004). Salmonella, stress responses and food safety. Nat Rev Microbiol 2, 504-509.

Jørgensen, F., Leach, S., Wilde, S. J., Davies, A., Stewart, G. S. \& Humphrey, T. (2000). Invasiveness in chickens, stress resistance and RpoS status of wild-type Salmonella enterica subsp. enterica serovar Typhimurium definitive type 104 and serovar Enteritidis phage type 4 strains. Microbiology 146, 3227-3235.

Justice, S. S., Hunstad, D. A., Cegelski, L. \& Hultgren, S. J. (2008). Morphological plasticity as a bacterial survival strategy. Nat Rev Microbiol 6, 162-168.

Karatzas, K. A. G., Hocking, P. M., Jørgensen, F., Mattick, K., Leach, S. \& Humphrey, T. J. (2008). Effects of repeated cycles of acid challenge and growth on the phenotype and virulence of Salmonella enterica. J Appl Microbiol 105, 1640-1648.

Klein, J. R., Fahlen, T. F. \& Jones, B. D. (2000). Transcriptional organization and function of invasion genes within Salmonella enterica serovar Typhimurium pathogenicity island 1 , including the $\operatorname{prgH}, \operatorname{prgI}, \operatorname{prgJ}, \operatorname{prgK}, \operatorname{org} A, \operatorname{org} B$, and $\operatorname{org} C$ genes. Infect Immun 68, 3368-3376.

Kubori, T., Matsushima, Y., Nakamura, D., Uralil, J., Lara-Tejero, M., Sukhan, A., Galán, J. E. \& Aizawa, S. I. (1998). Supramolecular structure of the Salmonella Typhimurium type III protein secretion system. Science 280, 602-605.

Leach, S. A., Williams, A., Davies, A. C., Wilson, J., Marsh, P. D. \& Humphrey, T. J. (1999). Aerosol route enhances the contamination of intact eggs and muscle of experimentally infected laying hens by Salmonella typhimurium DT104. FEMS Microbiol Lett 171, 203-207.

Lee, C. A. \& Falkow, S. (1990). The ability of Salmonella to enter mammalian cells is affected by bacterial growth state. Proc Natl Acad Sci U S A 87, 4304-4308.

Mattick, K. L., Jørgensen, F., Legan, J. D., Cole, M. B., Porter, J., Lappin-Scott, H. M. \& Humphrey, T. J. (2000). Survival and filamentation of Salmonella enterica serovar Enteritidis PT4 and Salmonella enterica serovar Typhimurium DT104 at low water activity. Appl Environ Microbiol 66, 1274-1279. 
Mattick, K. L., Phillips, L. E., Jørgensen, F., Lappin-Scott, H. M. \& Humphrey, T. J. (2003a). Filament formation by Salmonella spp. inoculated into liquid food matrices at refrigeration temperatures, and growth patterns when warmed. J Food Prot 66, 215-219.

Mattick, K. L., Rowbury, R. J. \& Humphrey, T. J. (2003b). Morphological changes to Escherichia coli O157:H7, commensal E. coli and Salmonella spp in response to marginal growth conditions, with special reference to mildly stressing temperatures. Sci Prog 86, 103-113.

Mor-Mur, M. \& Yuste, J. (2010). Emerging bacterial pathogens in meat and poultry: an overview. Food and Bioprocess Technology 3, 24-35.

Perrett, C. A. \& Jepson, M. A. (2007). Applications of cell imaging in Salmonella research. Methods Mol Biol 394, 235-273.

Perrett, C. A., Karavolos, M. H., Humphrey, S., Mastroeni, P., Martinez-Argudo, I., Spencer, H., Bulmer, D., Winzer, K., McGhie, E. \& other authors (2009). LuxS-based quorum sensing does not affect the ability of Salmonella enterica serovar Typhimurium to express the SPI-1 type 3 secretion system, induce membrane ruffles, or invade epithelial cells. J Bacteriol 191, 7253-7259.

Phillips, L. E., Humphrey, T. J. \& Lappin-Scott, H. M. (1998). Chilling invokes different morphologies in two Salmonella enteritidis PT4 strains. J Appl Microbiol 84, 820-826.

Rowley, G., Spector, M., Kormanec, J. \& Roberts, M. (2006). Pushing the envelope: extracytoplasmic stress responses in bacterial pathogens. Nat Rev Microbiol 4, 383-394.

Rychlik, I. \& Barrow, P. A. (2005). Salmonella stress management and its relevance to behaviour during intestinal colonisation and infection. FEMS Microbiol Rev 29, 1021-1040.

Saunders, M. P., Wu, G., Abuoun, M., Pan, Z., Anjum, M. \& Woodward, M. J. (2010). Optical genetic mapping defines regions of chromosomal variation in serovars of $S$. enterica subsp. enterica of concern for human and animal health. Epidemiol Infect (published online 22 September 2010).

Sivapalasingam, S., Friedman, C. R., Cohen, L. \& Tauxe, R. V. (2004). Fresh produce: a growing cause of outbreaks of foodborne illness in the United States, 1973 through 1997. J Food Prot 67, 2342-2353.

Temme, K., Salis, H., Tullman-Ercek, D., Levskaya, A., Hong, S. H. \& Voigt, C. A. (2008). Induction and relaxation dynamics of the regulatory network controlling the type III secretion system encoded within Salmonella pathogenicity island 1. J Mol Biol 377, 47-61.

Threlfall, E. J. (2000). Epidemic Salmonella typhimurium DT 104 - a truly international multiresistant clone. J Antimicrob Chemother 46, $7-10$.

Threlfall, E. J. (2002). Antimicrobial drug resistance in Salmonella: problems and perspectives in food- and water-borne infections. FEMS Microbiol Rev 26, 141-148.

Villar, R. G., Macek, M. D., Simons, S., Hayes, P. S., Goldoft, M. J., Lewis, J. H., Rowan, L. L., Hursh, D., Patnode, M. \& Mead, P. S. (1999). Investigation of multidrug-resistant Salmonella serotype Typhimurium DT104 infections linked to raw-milk cheese in Washington State. JAMA 281, 1811-1816.

Vojdani, J. D., Beuchat, L. R. \& Tauxe, R. V. (2008). Juice-associated outbreaks of human illness in the United States, 1995 through 2005. J Food Prot 71, 356-364.

Wall, P. G., Morgan, D., Lamden, K., Ryan, M., Griffin, M., Threlfall, E. J., Ward, L. R. \& Rowe, B. (1994). A case control study of infection with an epidemic strain of multiresistant Salmonella typhimurium DT104 in England and Wales. Commun Dis Rep CDR Rev 4, R130R135.

Wu, V. C. H. (2008). A review of microbial injury and recovery methods in food. Food Microbiol 25, 735-744.

Edited by: J. Cavet 